\title{
É Possível Falar eM \\ TEORIA NORMATIVA DIALÓgICA NO BRASIL?
}

\author{
MATHEUS HenRIQue dos SANTOS DA Escossia ${ }^{\dagger}$
}

RESUMO: O presente ensaio possui o objetivo de investigar a teoria dos diálogos constitucionais e sua aplicação no cenário jurídico-político brasileiro. Para tanto, toma-se por base a catalogação feita por Christine Bateup no artigo The Dialogic Promise, em que reparte tal teoria da seguinte maneira: i) de um lado, as empíricas (ou descritivas); ii) de outro, as normativas (ou prescritivas). Nesse sentido, o foco do presente trabalho repousa sobre essa segunda dimensão, de modo a avaliar se é adequado fazer uma mediação teórica em prol de uma teoria dialógica normativa brasileira e em que medida é pertinente tal construção. Para tanto, serão abordados quatro pontos que necessariamente essa mediação deve levar a sério, quais sejam: a) assimetria estrutural das relações sociais; b) pragmática linguística e controle discursivo (ou se é factível aproximar o diálogo institucional do diálogo entre cidadãos em uma democracia deliberativa); c) a sobreposição de funções pelo Supremo Tribunal Federal (STF), que simultaneamente opera como Corte Constitucional, corte recursal e jurisdição originária; d) “Nova Separação de Poderes". A hipótese a ser verificada é no sentido de que é inviável a construção de uma teoria dos diálogos constitucionais normativa brasileira que ultrapasse de maneira satisfatória os quatro pontos acima, sem que incorra em algum tipo de incongruência ou incompatibilidade. A justificativa desse percurso teórico se faz pertinente na exata medida em que as instituições agonizam em busca de legitimidade democrática, cuja conflituosidade política invariavelmente as colocam em xeque. A reflexão será conclusiva no sentido de aproximar os insights de uma teoria dialógica normativa à atuação das instituições, com especial ênfase na do STF, e de que modo os respectivos desenhos podem ser beneficiar desse esforço teórico.

\footnotetext{
${ }^{\dagger}$ Mestrando em Direito Público pela Universidade do Estado do Rio de Janeiro. Graduado pela Faculdade de Direito de Vitória. Advogado.
} 
Palavras-Chave: Diálogos Constitucionais; Democracia; Desenhos Institucionais; Interpretação.

ABSTRACT: The following paper aims to investigate the constitutional dialogues theory and its application in juridical and political Brazilian scenario. Therefore, we will move from the classification made by Christine Bateup, in her article called The Dialogic Promise, in which she splits the theory in the following manner: i) one side stands the empirical (or descriptive); ii) the other side stands the normative (or prescriptive). Then, the paper's main goal is over this second dimension, as we will evaluate if it is available to build a Brazilian dialogical normative theory and how should proceed. Therefore, we will approach four steps that these build has to be concerned: a) structural asymmetry over social relations; b) linguistic pragmatics and discursive control (or if it is workable to make a connection between the citizen dialogue and the institutional dialogue); c) the overlap concerning the Brazilian Supreme Court functions, that operates simultaneously as a Constitutional Court, appealing court and first jurisdiction; d) "New Separation of Powers". The hypothesis to be verified is about the possibility to build a Brazilian dialogical normative theory that surpasses in a satisfactory manner the four steps above, without falling into some incongruence or incompatibility. This theoretical pursuit is due the democratic legitimacy struggle seen through the institutions, since there is high political animosity. The reflection will be conclusive in order to approximate the insights of a normative dialogical theory and the institutions performance, especially the Brazilian Supreme Court, and will help to improve the institutional design after this theoretical effort.

KEYWORDS: Constitutional Dialogues; Democracy; Institutional Design; Interpretation. 


\section{SUMÁRIO:}

I. CONSIDERAÇÕES INICIAIS: SITUANDO O PROBLEMA ..........................977

II. 1' PASSO: SOBRE AS ASSIMETRIAS DAS RELAÇÕES SOCIAIS ..............982

III. 2 ${ }^{\circ}$ PASSO: DEMOCRACIA, INTERSUBJETIVIDADE E DISCURSO........989

IV. 3 PASSO: A SOBREPOSIÇÃO DE FUNÇÕES DO STF

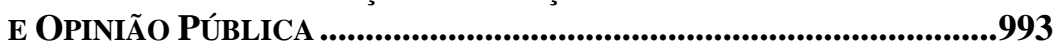

V. 4' Passo: "Nova SeParaÇão de PodereS" ....................................996

VI. CONCLUSÃO ......................................................................................999

VII. REFERÊNCIAS...........................................................................................999

\section{TABLE OF CONTENTS:}

I. PRELIMINARY CONSIDERATIONS: SITUATING THE PROBLEM .........977

II. ST $^{\text {ST }}$ STEP: ABOUT THE ASYMMETRIES IN SOCIAL RELATIONSHIPS...982

III. $2^{\text {ND }}$ STEP: DEMOCRACY, INTERSUBJECTIVITY AND DISCOURSE.....989

IV. $3^{\text {RD }}$ STEP: THE OVERPOSITIONING OF FUNCTIONS OS STF

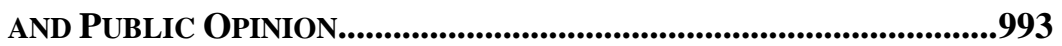

V. $\quad{ }^{\mathrm{TH}}$ STEP: "NEW SEPARATION OF POWERS" ....................................996

VI. CONCLUSION .....................................................................................................999

VII. REFERENCES ..........................................................................................999 


\section{CONSIDERAÇÕES INICIAIS: SITUANDO O PROBLEMA}

O protagonismo da jurisdição constitucional não é fenômeno novo no Brasil. Acompanhando o fenômeno mundial de expansão do papel das Cortes no desenho institucional ${ }^{1}$ na segunda metade do Século XX, os sinos dessa mudança paradigmática começaram a tilintar com a Constituição de 88.

Seja pela sofisticação dos mecanismos de controle de constitucionalidade $^{2}$, seja pelo pré-comprometimento ${ }^{3}$ do marco constitucional ${ }^{4}$ com diversos valores, por vezes colidentes entre si, o Supremo Tribunal Federal (STF) alcançou o referido status de protagonista no espaço jurídico-político brasileiro nas últimas duas décadas.

No entanto, os estudos sobre a legitimidade democrática por detrás de sua atuação persistem como um território marcado por incertezas. O conformismo de que o STF possui a última palavra em matéria de interpretação constitucional, "porque o art. 102, da Constituição Federal,

${ }^{1}$ GINSBURG, Tom; VERSTEEG, Mila. Why do Countries adopt constitutional review? The Journal of Law, Economics \& Organization, Vol. 30, 3, 2014; GINSBURG, Tom. The Global Spread of Constitutional Review. In: Keith Whittington; Daniel Keleman; Gregory Caldeira (eds.). Oxford Handbook of Law and Politics. New York, NY: Oxford University Press, 2008; STONE SWEET, Alec. Constitutional Courts. Yale Law School Public Law Working Paper, No. 233, 2011; HIRSCHL, Ran. The Political Origins of the New Constitutionalism. Indiana Journal of Global Legal Studies, Vol. $11,1,2004$.

${ }^{2}$ CRUZ, Álvaro Ricardo de Souza. Jurisdição Constitucional Democrática. $2^{\underline{a}}$ ed. Belo Horizonte, MG: Arraes Editores, 2014, p. 331 e ss.; VIEIRA, Oscar Vilhena. Supremo Tribunal Federal: Jurisprudência Política. $2^{a}$ ed. São Paulo, SP: Malheiros, 2002, p. 228.

${ }^{3}$ NINO, Carlos Santiago. The Constitution of Deliberative Democracy. New Haven, CT: Yale University Press, 1996, p. 117; ELSTER, Jon. Ulisses liberto: estudos sobre racionalidade, pré-compromisso e restrições. Trad. Cláudia Sant'Ana Martins. São Paulo, SP: Editora UNESP, 2009, p. 119-121; ELSTER, Jon. Ulysses and the Sirens: studies in rationality and irrationality. Cambridge, MA: Cambridge University Press, 1984, p. 22.

${ }^{4}$ BARROSO, Luís Roberto. A razão sem voto: o Supremo Tribunal Federal e o governo da maioria. Revista Brasileira de Políticas Públicas, Vol. 5, 2, 2015, p. 28; BARROSO, Luís Roberto. O Novo Direito Constitucional Brasileiro: contribuições para a construção teórica e prática da jurisdição constitucional no Brasil. Belo Horizonte, MG: Editora Fórum, 2013, p. 121. 
'disse' (SIC)", não mais se sustenta.

Por esse motivo, é crescente pesquisas no sentido de compreender como interpretar a interpretação do STF e dos demais atores políticos, tendo a democracia como questão fulcral subjacente.

Dentre os modelos teóricos que se prestam a tal finalidade, as teorias dialógicas ${ }^{5}{ }^{6}$ acendem como mais uma possibilidade de investigação do fenômeno. Em que pese diversas correntes dentre esse quadro mais amplo, o denominador comum entre elas repousa na recusa de uma supremacia, seja a legislativa, seja a judicial. Ou seja, a interpretação constitucional inevitavelmente acaba sendo cíclica e construída por todos os Poderes.

Christine Bateup, no artigo "The Dialogic Promise"7, faz um percurso sobre as possíveis teorias que poderiam ser catalogadas como dialógica. A autora conclui que o modelo dialógico ideal (ou mais promissor) conglobaria as teorias dialógicas de equilíbrio, que em linhas gerais tenta enxergar a discussão constitucional num papel amplo de interação entre o Judiciário e a sociedade, e as teorias dialógicas de parceria, que por sua vez se assentam numa espécie de departamentalismo (ou que cada Poder é mais apto a resolver certas questões).

A visão mais promissora de diálogo constitucional e, consequentemente, a

${ }^{5}$ No Brasil, quatro autores (e cinco obras) notadamente se debruçaram sobre o tema: 1 ) SAMPAIO, Marco Aurélio. Medida Provisória, Diálogo Constitucional e a Falácia de Usurpação de Poderes Legislativos pelo Executivo. Revista de Direito do Estado, Vol. 1, 4, 2006; SAMPAIO, Marco Aurélio. A Medida Provisória no Presidencialismo Brasileiro. São Paulo: Malheiros, 2007; 2) MENDES, Conrado Hübner. Direitos Fundamentais, Separação de Poderes e Deliberação. São Paulo, SP: Saraiva, 2011;3) BRANDÃO, Rodrigo. Supremacia Judicial versus diálogos constitucionais: a quem cabe a última palavra sobre o sentido da Constituição? Rio de Janeiro, RJ: Lumen Juris, 2012; 4) ABRAMOVAY, Pedro. Separação de Poderes e Medidas Provisórias. Rio de Janeiro, RJ: Elsevier, 2012.

${ }^{6}$ Nos Estados Unidos, o precursor do tema foi Louis Fisher, em 1988. Cf. FISHER, Louis. Constitutional Dialogues: Interpretation as Political Process. Princeton, NJ: Princeton University Press, 1988. No Canadá, Peter Hogg e Alisson Bushell, em 1997. HOGG, Peter; BUSHELL, Alisson. The Charter Dialogue between Courts and Legislatures (Or Perhaps the Charter of Rights isn't such a bad thing after all). Osgoode Hall Law Journal, Vol. 35, 1, 1997, p. 75-124.

${ }^{7}$ BATEUP, Christine. The Dialogic Promise: assessing the normative potential of Theories of Constitutional Dialogue. Brooklyn Law Review, Vol. 71, 3, 2006, p. 11091180. 
abordagem normativa mais forte do papel da revisão judicial no constitucionalismo moderno emerge quando os entendimentos de equilíbrio e parceria são combinados. De outro lado, essa síntese ajudar a resolver a prolongada preocupação com a legitimidade democrática com o modelo de parceria. Mais importante, essa via de mão dupla autoriza um entendimento mais compreensivo de diferentes aspectos institucionais e sociais do diálogo constitucional, e os vários únicos meios de que diferentes atores participam na busca pelo significado constitucional. ${ }^{8}$

Muito embora essa conclusão seja suscetível de críticas, assim como a categorização feita pela autora ao longo do texto, a principal contribuição da autora para o presente trabalho passa pela seguinte classificação das teorias dialógicas ${ }^{9}$ i) de um lado, as empíricas (ou descritivas); ii) de outro, as normativas (ou prescritivas).

Diversos exemplos são aptos a referendar a abordagem empírica. Vamos a eles.

i) Na relação entre Judiciário e Legislativo, os mecanismos de superação legislativa (overrides) ${ }^{10}$, embora pareçam desembocar para um cenário de supremacia legislativa, podem refletir um caráter dialógico. Sobre a realidade brasileira, há o exemplo do foro por prerrogativa de função.

Durante muito tempo, vigorou no STF a Súmula 394, que conferia foro privilegiado nos casos de crimes comuns cometidos durante o exercício funcional (e caso houvesse previsão da prerrogativa da autoridade que cometeu), mesmo que ação penal iniciada depois de cessada a função.

Em 2001, o STF superou sua jurisprudência, revogando a Súmula, passando a prerrogativa de função ser "móvel", sendo a autoridade processada conforme esteja investida no cargo/função (trata-se do princípio da atualidade da função ${ }^{11}$ ).

Em 2002, porém, foi promulgada a Lei 10.628, restaurando o

${ }^{8}$ BATEUP, Christine. The Dialogic Promise: assessing the normative potential of Theories of Constitutional Dialogue. Brooklyn Law Review, Vol. 71, 3, 2006, p. 1174. ${ }_{9}$ BATEUP, Christine. The Dialogic Promise: assessing the normative potential of Theories of Constitutional Dialogue. Brooklyn Law Review, Vol. 71, 3, 2006, p. 10 ${ }^{10}$ HIEBERT, Janet. Charter conflicts: what is the Parliament role? Montreal: McGillQueen's University Press, 2002, p. 62 e ss.; e HIEBERT, Janet. Enriching Constitutional Dialogue: viewing Parliament's role as both proactive and reactive. Ottawa: Research and Statistics Division, 2000.

${ }^{11}$ BADARÓ, Gustavo Henrique. Processo Penal. $3^{\text {a }}$ ed. São Paulo, SP: Ed. Revista dos Tribunais, 2015, p. 244. 
entendimento da Súmula, mantendo a prerrogativa se o crime praticado no exercício funcional, mesmo que não mais investido a autoridade no cargo. Em 2005, mais uma reviravolta. A Ação Direta de Inconstitucionalidade (ADI) $2.797^{12}$ declarou a inconstitucionalidade formal da referida lei, modulando, porém, prospectivamente os efeitos a partir de 15 de setembro de $2005^{13}$, de forma que os processos contemplados pela Lei reputada inconstitucional no período de 2002 até 2005 fossem preservados.

No entanto, esses não foram os capítulos derradeiros da "conversa" entre Congresso e STF. Pelo contrário, em 2004, foi criada a Lei 11.036, cujo art. $2^{\underline{ }}$ não apenas equiparava o cargo de Presidente do Banco Central a Ministro de Estado, como também trazia expressamente a previsão de que o foro por prerrogativa de função alcançava os ex-Presidentes.

Diferentemente do que se passou com a reforma do Código de Processo Penal mencionada acima, a Lei 11.036/04 foi reputada constitucional, no julgamento da ADI $3.289^{14}$. E a ratio decidendi que predominou foi a do voto vencido da ADI 2.797. Típico exemplo de overruling. Ou talvez mais um típico exemplo da falta de apreço do STF a sua própria jurisprudência. Tal como diria Caetano Veloso, "porque és o avesso, do avesso, do avesso, do avesso...".

ii) Na relação Executivo e Legislativo, mencione-se o ainda persistente presidencialismo de coalizão ${ }^{15}$. Em linhas gerais, a sustentação política da Presidência se dá a partir da base construída com o Legislativo, que se faz presente em três principais momentos ${ }^{16}$ : a) durante o período eleitoral, cuja coalizão se presta ao maior tempo de televisão, sobretudo; $b$ ) durante a formação do governo, com a partilha das pastas ministeriais; c) durante

${ }_{12}$ STF, ADI 2.797/DF, Min. Rel. Sepúlveda Pertence, Tribunal Pleno. Julgamento em: $15 / 09 / 2005$.

${ }^{13}$ STF, ED-ADI 2.797/DF, Min. Rel. para Acórdão Ayres Britto, Tribunal Pleno. Julgamento em: 16/05/2012.

${ }_{14}$ STF, ADI 3.289/DF, Min. Rel. Gilmar Mendes, Tribunal Pleno. Julgamento em: 05/05/2005.

${ }^{15}$ ABRANCHES, Sérgio Henrique. Presidencialismo de Coalizão: o dilema institucional brasileiro. Dados: Revista de Ciências Sociais, Vol. 31, 1, 1988, p. 19 e ss; e CHEIBUB, José Antonio; PRZEWORSKI, Adam; SAIEGH, Sebastian. Governos de coalizão nas democracias presidencialistas e parlamentaristas. Dados: Revista de Ciências Sociais, Vol. 45, 2, 2002, p. 187-218. ${ }^{16}$ SAMPAIO, Marco Aurélio. A Medida Provisória no Presidencialismo Brasileiro. São Paulo: Malheiros, 2007, p. 125. 
a execução da pauta e agenda políticas.

Diante desse quadro, é insofismável que a governabilidade se apoia em uma dinâmica de cooperação e dialógica entre os Poderes, ainda que seja marcada por tensões, dado o pluripartidarismo no Brasil.

iii) Entre Judiciário e Executivo, a modelagem a partir da judicialização de políticas públicas ${ }^{17}$. Além disso, especialmente tomando por base o direito processual coletivo, o Ministério Público e a Defensoria Pública são importantes atores nesse "diálogo", em que a intepretação constitucional acerca dos direitos sociais se desloca para a dimensão dos inputs $^{18}$ (ou quais seriam os mecanismos de implementação da política pública).

Os exemplos descritivos da dimensão empírica dos diálogos constitucionais existem, são inesgotáveis e são conclusivos no sentido de demonstrar a viabilidade dessa teoria no caráter descritivo.

$O$ verdadeiro desafio, nesse sentido, se assenta em questionar a transposição da dimensão normativa no Brasil.

É bem verdade que a mediação de qualquer teoria estrangeira é marcada por desafios, até porque os teóricos pautaram sua análise em fenômenos com peculiaridades que não coincidem com a realidade brasileira. A matriz jurídica do common law e o apreço pelos precedentes são características marcantes do Canadá e dos Estados Unidos, países em que as teorias dialógicas gestaram.

De maneira oposta, as assimetrias sociais são constitutivas da realidade brasileira. Seria esse um fator determinante e impeditivo para a "importação" da teoria?

E mais. Por mais que os Diálogos Constitucionais tenham um recorte metodológico específico, qual seja as interações que se sucedem entre as instituições (com ênfase nos 3 Poderes), essa teoria convive com outras teorias que possuem o "diálogo" como foco, para além do viés institucional. Isso seria relevante para a mediação?

Por isso se lança a seguinte pergunta: é possível falar de teoria normativa dialógica no Brasil?

${ }_{17}$ JORDÃO, Eduardo; ROSE-ACKERMAN, Susan. Judicial Review of Executive Policymaking in advanced democracies: beyond rights review. Administrative Law Review, Vol. 66, 1, 2014.

${ }^{18}$ NORTON, Andrew; ELSON, Diane. What's behind the budget? Politics, rights and accountability in the budget process. London: Overseas Development Institute, 2002, p. 30-31. 
O presente ensaio está estruturado em quatro passos, que coincidem com as próximas quatro seções, cuja argumentação deve preencher duas linhas argumentativas:

a) Se outros modelos propositivos de como deve ser a interpretação constitucional teriam uma performance melhor do que a teoria dialógica, dada as peculiaridades da realidade brasileiras;

b) Se o modelo dialógico for o ideal, como é possível importá-lo e adequá-lo, de modo, inclusive, a aprimorar a dinâmica dialógica (que já se verifica em uma dimensão empírica, conforme visto acima).

São quatro os passos para análise da teoria:

Primeiro passo: irá se avaliar de que modo a assimetria estrutural das relações sociais é fator determinante na mediação de uma teoria que se originou em uma realidade notadamente diversa da que se presencia no Brasil.

Segundo passo: a característica do "diálogo" não é exclusividade das teorias dialógicas interinstitucionais, de modo que aquele conceito é significativo para teorias democráticas que se pautem na intersubjetividade. Por isso, é relevante se questionar se há alguma simbiose entre elas.

Terceiro passo: a sobreposição de funções do STF é uma realidade, já que opera simultaneamente como corte constitucional, corte recursal e juízo originário de determinadas ações (cite-se a prerrogativa de função para julgamento de crimes comuns, mencionada acima). A sobreposição desempenha algum papel na mediação da teoria?

Quarto passo: a complexidade da sociedade atual é deveras mais acentuada que as visões de Locke e Montesquieu acerca das funções de cada Poder. Tomando como premissa a caracterização de uma "Nova Separação de Poderes", bem como o desenho institucional brasileiro, de que maneira a teoria dialógica normativa brasileira operaria?

\section{1o PASSO: SOBRE AS ASSIMETRIAS DAS RELAÇÕES SOCIAIS}

Dentre os diversos problemas sociais que o Brasil enfrenta, a desigualdade é ponto de partida e/ou de chegada de todos. A assimetria 
nas relações sociais entre os "subintegrados" e "sobreintegrados"19 ou entre os "invisíveis, demonizados e imunes" ${ }^{20}$ deságua na ordem jurídica, a qual inevitavelmente opera numa lógica reflexiva que acaba por reproduzir essa desigualdade.

As disparidades no Brasil são renitentes e multifacetadas. Tome-se como base a questão de gênero. No segundo trimestre de $2016^{21}$, as taxas de ocupação das pessoas com idade para trabalhar demonstram uma primazia do sexo masculino em todas as regiões (no Norte, por exemplo, a proporção dos trabalhadores ocupados é de $61 \%$ homens e $39 \%$ mulheres). No entanto, as mulheres representam uma fatia maior na população com idade para trabalhar (a partir de 14 anos), representando $52,2 \%$.

Uma análise meramente superficial desses dois indicadores já denota que o desemprego é mais sentido pelas mulheres do que pelos homens. Ou seja, as consequências primeiras das crises econômicas, quais sejam o arrefecimento da economia e o fechamento de postos de trabalho, não possuem impacto igual por entre a população.

E essa desigualdade também se transborda para a política. As mulheres ocupam um percentual pífio na representatividade parlamentar. São 51 deputadas federais, ao passo que há 461 deputados federais (9\% da Câmara dos Deputados) e são 13 senadoras, ao passo que há 68 senadores (10\% no Senado). ${ }^{22}$ Acentue-se esse cenário com a falta

${ }^{19}$ Essas duas expressões são cunhadas por Marcelo Neves e refletem como a ordem jurídica opera de maneira diferente, a variar do grupo em que cada um faz parte. Com os subintegrados, o direito "joga contra", é opressivo. Com os sobreintegrados, o direito "joga a favor", está a seu serviço. NEVES, Marcelo. Entre Têmis e Leviatã: uma relação difícil. 3ª ed. São Paulo, SP: Wmf Martins Fontes, 2012, p. 248-250.

${ }^{20}$ Essa tríade é cunhada por Oscar Vilhena Vieira e retrata também a mesma inquietude de Neves na interface direito e desigualdade. VIEIRA, Oscar Vilhena. A desigualdade e a subversão do Estado de Direito. In: Daniel Sarmento; Daniela Ikawa; Flávia Piovesan. Igualdade, Diferença e Direitos Humanos. Rio de Janeiro, RJ: Lumen Juris, 2008, p. 207 e ss.

${ }^{21}$ Sobre esses dados Cf. BRASIL, INSTITUTO BRASILEIRO DE GEOGRAFIA E ESTATÍSTICA (IBGE). Pesquisa Nacional por Amostra de Domicílios Contínua: $\mathbf{2}^{\circ}$ trimestre 2016. Disponível em: <http://www.ibge.gov.br/home/estatistica/pesquisas/anos anteriores 2016.shtm>. Acesso em: 05 de outubro de 2016. ${ }^{22}$ Cf. $<$ http://www.reformapolitica.org.br/noticias/artigos/1602-as-consequencias-dasub-representacao-das-mulheres-nos-espacos-de-poder-html $>$. Acesso em: 18 de julho 
de mulheres na gestão ministerial do atual Presidente da República ${ }^{23}$, Michel Temer, cuja primeira mulher ${ }^{24}$, Grace Mendonça, só foi nomeada após quatro meses de governo.

Ainda sobre a desigualdade, as assimetrias econômicas persistem inexpugnáveis e "ditando o ritmo" de como as assimetrias sociais se constroem. O índice de Gini no Brasil, o qual se ocupa em mensurar a concentração de renda no Brasil, é de 0,498 25 -26, sendo que o referencial 0 é o valor ideal da igualdade ao passo que 1 é o da desigualdade. Em que pese a taxa de evolução ser verificável nesse indicador (por exemplo, em 2001, o índice era de 0,563), o coeficiente demonstra como o país ainda é marcado pela desigualdade.

E mais uma vez, a desigualdade no plano econômico transborda para o plano político. O perfil dos parlamentares referenda essa assertiva. No Senado, em trabalho que analisou 54 legislaturas do Senado brasileiro ${ }^{27}$, as profissões mais expressivas eram: advogados, empresários (se somados os urbanos e rurais, o número fica ainda mais expressivo) e professores. Assim, infere-se que a representatividade nessa Casa está longe de representar uma moldura popular.

Na Câmara dos Deputados o cenário não é outro ${ }^{28} .52$ deputados

de 2016. Cf. <http://politica.estadao.com.br/noticias/geral,brasil-tem-menos-mulheresno-legislativo-que-oriente-medio,1645699>. Acesso em: 18 de julho de 2016.

${ }^{23}$ Cf. <http://www.bbc.com/portuguese/brasil/2016/05/160511 aliados temer ms cc $>$. Acesso em: 05 de outubro de 2016.

${ }^{24}$ Cf. $<$ http://oglobo.globo.com/brasil/michel-temer-confirma-grace-mendonca-paraagu-20077950>. Acesso em: 05 de outubro de 2016.

${ }^{25}$ BRASIL, INSTITUTO BRASILEIRO DE GEOGRAFIA E ESTATÍSTICA (IBGE).

Pesquisa Nacional por Amostra de Domicílios (PNAD): Brasil e Síntese de Indicadores 2013. Disponível em:

$<<$ http://www.ibge.gov.br/home/estatistica/populacao/trabalhoerendimento/pnad2013/ $>$. Acesso em: 05 de outubro de 2016, p. 57.

${ }^{26}$ Esse é o último dado identificado a partir do PNAD. A Secretaria de Política Econômica do Ministério da Fazendo lançou estudo em 2016, com dados no sentido de que o índice é de 0,490. Cf. <http://www.fazenda.gov.br/noticias/2016/maio/200bspedivulga-relatorio-sobre-a-distribuicao-da-renda-no-brasil >. Acesso em: 05 de outubro de 2016.

${ }^{27}$ NEIVA, Pedro; IZUMI, Maurício. Perfil profissional e distribuição regional dos senadores brasileiros em dois séculos de história. Revista Brasileira de Ciências Sociais, Vol. 29, 84, 2014, p. 165-188.

${ }^{28}$ Os números a seguir são contabilizados a partir da lista com as informações dos deputados federais, divulgada pela própria Câmara dos Deputados, atualizada em 
federais se declaram como empresários ${ }^{29}$ (pouco mais que $10 \%$ da representação), 82 são advogados (e outros 11 bacharéis em direito, que somados perfazem quase $20 \%$ da representação) e 33 são médicos (pouco mais de $6 \%$ da representação). Por outro lado, há apenas 10 que se declaram como agricultore ${ }^{30}$ (pouco menos de $2 \%$ da representação).

Obviamente esses números não são conclusivos de que essa é a causa fundante (ou consequência) para as assimetrias estruturais no Brasil. Todavia, quando se analisa os números supracitados em conjunto com as cifras por detrás do financiamento das campanhas eleitorais ${ }^{31}$, não seria despropositado afirmar que o processo político tem sido notadamente um processo elitista, catalisador de uma "fissura" na relação entre representantes e representados.

Basicamente, a linha de raciocínio é a seguinte: a desigualdade social presente na sociedade brasileira transborda para a desigualdade na representação política. Por sua vez, o direito, produto típico da atuação da classe política, se presta a duas funções: i) oferecer o arcabouço normativo para a justificação das desigualdades e manutenção do status quo; ii) cristalizar as desigualdades que passam a ser constitutivas da própria criação e aplicação das normas jurídicas.

O exemplo mais claro repousa sobre a caracterização do bem jurídico no direito penal, especialmente acerca dos crimes ambientais e

06/10/2016, na seguinte página virtual:

$<$ www.camara.leg.br/internet/deputado/deputado.xls $>$.

${ }^{29}$ É bem verdade que vários que se declaram como tal, possuem mais de uma profissão. Exemplifique-se o Dep. Marcos Abrão (PPS/GO), que também é economista, bem como o Dep. Jaime Martins (PSD/MG), que também é engenheiro e advogado.

${ }^{30}$ Número que não necessariamente indica que o parlamentar irá prestigiar os interesses dos trabalhadores rurais ou do pequeno produtor, ao invés dos empresários rurais.

${ }^{31} \mathrm{O}$ financiamento por pessoas jurídicas foi proibido, tal como observado nas eleições de 2014. No entanto, o financiamento privado ainda era permitido, desde que feito por pessoas físicas. Esse fato não gerou uma "modéstia" nos gastos, embora as quantias tenham sido menores do que em 2012. João Dória, que foi eleito prefeito de São Paulo, teve um custo de campanha de $\mathrm{R} \$ 13.969 .471,48$, sendo que ele foi o maior doador para sua própria campanha, com a quantia de $\mathrm{R} \$ 2.934 .100,00$, o equivalente a $39 \%$. Cf. $<$ http://www.tse.jus.br/eleicoes/eleicoes-2016/divulgacao-de-candidaturas-e-contaseleitorais2>. Ainda sobre financiamento de campanha, cf. SARMENTO, Daniel; OSORIO, Aline. Eleições, Dinheiro e Democracia: a ADI 4.650 e o modelo brasileiro de financiamento de campanhas eleitorais. Direitos Fundamentais \& Justiça, Ano 8, no 26, 2014, p. 15-38.

2 JOURNAL OF INSTITUTIONAL STUDIES 2 (2016) 
tributários, cujos destinatários são imediatamente diversos dos crimes contra o patrimônio do Código Penal. Frise-se, como exemplo, lançamento do crédito tributário como condição de procedibilidade da ação penal e o parcelamento como causa de extinção de punibilidade ${ }^{32}$. Não é necessário ir além do senso comum para perceber que a ocorrência desse tipo de crime é mais presente entre os estratos sociais mais abastados, de modo que os principais destinatários dos crimes contra o patrimônio ocupam a parcela mais pobre ${ }^{33}$.

Ora, se a ordem jurídica é reprodutora da desigualdade e se essa mesma ordem jurídica é que funda as instituições, seria de se esperar que as instituições reforçariam ou reformariam o cenário de desigualdade?

A desigualdade social pode ser tida como o principal desafio para a mediação de qualquer teoria para o Brasil. Com a teoria dialógica normativa não pode ser diferente.

Esse tópico passou desapercebido pelos autores que se debruçaram sobre o tema, até porque o núcleo das discussões avaliava muito mais o aspecto institucional no tocante à interpretação constitucional, do que propriamente "qual seria o papel do povo" 34 nessa dinâmica.

E curiosamente, a igualdade foi um valor exaustivamente debatido por autores que se inclinam em prol de um modelo de supremacia de interpretação constitucional. Fiquemos com dois: Jeremy Waldron e

32 STRECK, Lenio Luiz. Bem jurídico e Constituição: da Proibição de Excesso (Übermassverbot) à Proibição de Proteção Deficiente (Untermassverbot) ou de como não há blindagem contra normas penais inconstitucionais. Boletim da Faculdade de Direito (Universidade de Coimbra), Vol. LXXX, 2004, p. 303-345

${ }^{33}$ Crimes contra o patrimônio (97.605 crimes) e crimes tipificados na Lei de Drogas (66.313 crimes) são os crimes mais "populares" cometidos pela população carcerária brasileira, de acordo com o último levantamento do DEPEN. BRASIL, MINISTÉRIO DA JUSTIÇA, DEPARTAMENTO PENITENCIÁRIO NACIONAL (DEPEN). Levantamento Nacional de Informações Penitenciárias INFOPEN: Junho de 2014. Disponível em: $<$ http://www.justica.gov.br/noticias/mj-divulgara-novo-relatorio-doinfopen-nesta-terca-feira/relatorio-depen-versao-web.pdf $>$. Acesso em: 06 de outubro de 2016.

${ }^{34}$ Apesar de o conteúdo da democracia, mais precisamente a legitimidade democrática da interpretação constitucional capitaneada por cada instituição, ser premissa de todos os autores que se filiam a essa corrente. "This dialogue between and accountability of each of the branches have the effect of enhancing the democratic process, not denying it." Trad. Livre: “Esse diálogo e accountability entre os Poderes possui o efeito de aprimorar o processo democrático, não negar." ROACH, Kent. The Supreme Court on trial: judicial activism or democratic dialogue. Toronto: Irwin Law, 2001, p. 176. 
Ronald Dworkin.

Situada em meio a outros valores, a igualdade desempenhava papel crucial nas teorias desses autores. Waldron via com ceticismo a revisão judicial de constitucionalidade (constitutional judicial review), de modo que a instituição mais adequada para superar os desacordos seria o Legislativo, conduzido pelo princípio majoritário, já que seria o meio adequado para concretizar o princípio da igualdade e pluralidade de opinião.

But I want to stress the regards in which majority-decision respects the individuals whose votes it aggregates. It does so in two ways. First, it respects their differences of opinion about justice and the common good [...] Second, it embodies a principle of respect for each person in the processes by which we settle on a view to be adopted as ours even in the face of disagreement. ${ }^{35}$

Por outro lado, Dworkin formula um conceito constitucional de democracia $^{36}$ (ou concepção de parceria), em que a igualdade de consideração entre os membros é condição moral para sua caracterização.

A concepção de parceira da democracia é diferente; afirma que o conceito de governo democrático significa um governo não pela maioria das pessoas que exercem autoridade sobre todas as pessoas, mas pelas pessoas, que agem como um todo enquanto parceiras. Esta deve ser, certamente, uma parceria que se divide em relação à política, uma vez que a unanimidade é rara nas comunidades políticas, sejam quais forem as suas dimensões. No entanto, pode ser uma parceria, se os membros admitirem que, na política, têm de agir com respeito e preocupação iguais por todos os outros parceiros. $[\ldots]^{37}$

A partir dessa construção, democracia constitucional não pode ser dissociada de um conteúdo moral intrínseco. Por isso a necessidade de

35 “Mas eu quero enfatizar os aspectos os quais a decisão majoritária respeita os indivíduos que agregaram seus votos. E o faço de duas maneiras. Primeiro, a decisão majoritária respeita as diferenças de opinião sobre justiça e bem comum [...] Segundo, a decisão majoritária encarna o princípio do respeito a cada pessoa no processo de decisão que assenta o ponto de vista de cada pessoa como uma decisão nossa, apesar do desacordo" (tradução livre). WALDRON, Jeremy. Law and Disagreement. New York, NY: Oxford University Press, 1999, p. 109.

${ }^{36}$ DWORKIN, Ronald. O Direito da Liberdade: a leitura moral da Constituição norteamericana. Trad. Marcelo Brandão Cipolla. São Paulo, SP: Martins Fontes, 2006, p. 26. ${ }^{37}$ DWORKIN, Ronald. Justiça para ouriços. Trad. Pedro Elói Duarte. Coimbra: Almedina, 2011, p. 392. 
uma instituição que seja capaz a conferir a última palavra a acerca da interpretação constitucional, ou seja, exercer uma "leitura moral da Constituição". Para Dworkin, essa instituição é o Judiciário ${ }^{38}$.

Independente das críticas e desacertos das teorias desses dois autores, é inegável que seus dois modelos de interpretação possuem uma preocupação com o critério da igualdade que as teorias dialógicas sonegam.

Nesse sentido, o primeiro passo para que se possa admitir uma teoria dialógica normativa brasileira é que ela tenha um cuidado acerca das assimetrias estruturais discorridas no presente tópico. Algumas considerações podem contribuir para a mediação:

1) Reforço dos instrumentos de participação popular nos processos constitucionais judiciais, por exemplo, necessidade de que os argumentos trazidos em audiências públicas e pelo amicus curiae façam parte da fundamentação dos magistrados, nem que seja para rechaçar;

2) Ampliação da utilização dos instrumentos de democracia direta, tais como as leis de iniciativa popular, referendo e plebiscito. Necessidade de que mais vezes a população seja instigada a se manifestar sobre temas de ordem constitucional;

3) Controle de agenda política pelo povo. Esse é possivelmente um dos temas mais sensíveis da democracia, em que os (des)caminhos sempre ficam na ventura das autoridades (por exemplo, as pautas do STF e as sessões legislativas). As teorias dialógicas poderiam contribuir para lançar luzes a esse aspecto que habitualmente é esquecido pela doutrina.

Note que as três considerações tentam expandir a dimensão de como o povo ${ }^{39}$ pode contribuir para a interpretação constitucional. E a pergunta que se sucede é: mas de que modo a interpretação constitucional é capaz

${ }^{38}$ DWORKIN, Ronald. O Direito da Liberdade: a leitura moral da Constituição norteamericana. Trad. Marcelo Brandão Cipolla. São Paulo, SP: Martins Fontes, 2006, p. 2-3. ${ }^{39}$ HÄBERLE, Peter. Hermenêutica Constitucional: a sociedade aberta dos intérpretes da Constituição. Contribuição para a interpretação pluralista e "procedimental" da Constituição. Trad. Gilmar Ferreira Mendes. Porto Alegre, RS: S.A. Fabris Editor, 2002; e KRAMER, Larry. Popular Constitutionalism, circa 2004. California Law Review, Vol. 92, 4, 2004, p. 959-1012. 
de mitigar as desigualdades?

É evidente que esse esforço transcende gerações e está para além do texto constitucional, já que envolve educação, políticas públicas, entraves culturais... de qualquer forma, a participação a partir da interpretação do que seja o conteúdo constitucional não pode virar as costas para seu principal destinatário, tampouco pode ficar refém do que as instituições devem decidir. Por isso, é necessário que a teoria dialógica dê conta de fornecer um arcabouço que contemple: democracia, povo e desigualdade. Esse deve ser o pano de fundo em que se opera os diálogos interinstitucionais.

\section{2o PASSO: Democracia, INTERSUbJeTIVIDADE E Discurso}

O primeiro passo versou sobre uma característica da sociedade brasileira que é reflexiva, como se observou, no direito e nas instituições. Assim, a mediação da teoria dialógica deva levar a sério a assimetria estrutural das relações sociais.

O segundo passo não foge da interface entre sociedade e interpretação constitucional. Curiosamente, a teoria dos diálogos constitucionais foi desenvolvida sem qualquer correlação com as teorias que fizesse conexão com a intersubjetividade. A maior parte das teorias dialógicas se fundam em uma conversa entre instituições, tendo como pano de fundo subjacente a troca de razões quando da interpretação constitucional.

Por outro lado, alguns autores que tratam de democracia em seus estudos lançam luzes sobre a questão da legitimidade democrática a partir do entendimento e diálogo entre os cidadãos. Nesse contexto, Habermas $^{40}$, Alexy ${ }^{41}$ e Pettit ${ }^{42}$ são exemplos de como a comunicação é indissociável do entendimento ${ }^{43}$ e, por conseguinte, a democracia se

${ }^{40}$ HABERMAS, Jürgen. Facticidad y Validez: sobre el Derecho y el Estado Democrático de Derecho en términos de Teoría del Discurso. Trad. Manuel Jiménez Redondo. $6^{\mathrm{a}}$ ed. Madrid: Trotta, 2010.

${ }^{41}$ ALEXY, Robert. Teoría de la Argumentación Jurídica: la Teoría del Discurso

Racional como Teoría de la Fundamentación Jurídica. Trad. Manuel Atienza e Isabel Espejo. Madrid: Centro de Estudios Constitucionales, 1997.

42 PETTIT, Philip. Teoria da Liberdade. Trad. Renato Sérgio Pubo Maciel. Belo Horizonte, MG: Del Rey, 2007.

${ }^{43}$ Sobre a diferença entre entendimento e acordo em Habermas, cf. nota de rodapé acima. NEVES, Marcelo. Entre Têmis e Leviatã: uma relação difícil. $3^{a}$ ed. São Paulo, SP: Wmf Martins Fontes, 2012. 
perfaz a partir desse elemento.

La razón comunicativa empieza distinguiéndose de la razón práctica porque ya no queda atribuida al actor particular o a un macrosujeto estatal-social. Es más bien el medio lingüístico, mediante el que se concatenan las interacciones y se estructuran las formas de vida, el que hace posible a la razón comunicativa. Esta racionalidad viene inscrita en el telos que representa el entendimiento intersubjetivo y constituye un ensemble de condiciones posibilitantes a la vez que restrictivas. [...] Entre otras cosas, tiene que partir de que los participantes persiguen sin reservas sus fines ilocucionarios, ligan su acuerdo al reconocimiento intersubjetivo de pretensiones de validez susceptibles de crítica y se muestran dispuestos a asumir las obligaciones relevantes para la secuencia de interacción que se siguen de un consenso. [... $]^{44}$

O presente ensaio não possui a pretensão de realizar uma análise exaustiva dos três autores, até porque fugiria do objeto que se pretende investigar, bem como exigiria um poder de síntese valoroso para reunilos em poucas dezenas de páginas. No entanto, suas ilações teóricas acerca da importância do discurso talvez sejam úteis para a mediação da teoria dialógica.

Habermas, por exemplo, condiciona a aceitação dos potenciais destinatários das normas como condição de sua validade ${ }^{45}$. Trata-se da

44 “A razão comunicativa começa se distinguindo da razão prática porque já não é atribuída a um ator particular ou a um macrosujeito estatal-social. É mais o meio linguístico, mediante o que se concatenam as interações e de estruturam as formas de vida, o que faz possível a razão comunicativa. Esta racionalidade vem inscrita no telos que representa o entendimento intersubjetivo e constitui um ensemble de condições possibilitantes em vez de restritivas. [...] Entre outras coisas, tem que partri de que os participantes perseguem sem reservas seus fins ilocucionários, ligando seu acordo ao reconhecimento intersubjetivo de pretensões de validez, suscetíveis de crítica e se mostram dispostos a assumir as obrigações relevantes para a sequência de interação que se seguem um consenso. [...]" (tradução livre). HABERMAS, Jürgen. Facticidad y Validez: sobre el Derecho y el Estado Democrático de Derecho en términos de Teoría del Discurso. Trad. Manuel Jiménez Redondo. $6^{\underline{a}}$ ed. Madrid: Trotta, 2010, p. 65-66.

${ }^{45}$ HABERMAS, Jürgen. Facticidad y Validez: sobre el Derecho y el Estado

Democrático de Derecho en términos de Teoría del Discurso. Trad. Manuel Jiménez Redondo. 6a ed. Madrid: Trotta, 2010, p. 100. 
ideia do "princípio dos afetados"46, em que a legitimidade do direito passa por seu reconhecimento racional dentro da comunidade, tomando como base a razão comunicativa ${ }^{47}$.

Pettit, partilhando de premissas semelhantes ao construir sua teoria da liberdade (política), se finca a uma ideia de "controle discursivo", que, em linhas gerais, consiste na percepção de que problemas comuns podem ser resolvidos coletivamente a partir do discurso.

Quando raciocinamos juntos, temos tipicamente uma influência de tomada de decisões um a respeito do outro, e alguns podem ter uma maior influência do que outros. Os mais influentes poderão ter um impacto sobre os demais, de inúmeras formas [...] A influência alcançada em tais movimentos pode ou não nos conduzir a uma maior iluminação interior e pode ou não suportar um eventual consenso. Mas possuindo ou não tais características, ela tem a influência de um co-raciocinador. $[\ldots]^{48}$

Pode até parecer contraintuitivo assimilar liberdade com a necessidade de tê-la reconhecida através do discurso. No entanto, Pettit assume que a pessoa já pode ser considerada livre, mesmo que perceba (tenha a consciência) de que está submissa à influência discursiva dos outros $^{49}$. Frise-se, nesse contexto, que o recorte feito por Pettit está no campo das liberdades políticas.

Alexy também se vale de categorias linguísticas para a formulação de sua teoria. Essa aproximação é basicamente a razão de ser de sua intersecção entre direito e moral.

${ }^{46}$ HABERMAS, Jürgen. Facticidad y Validez: sobre el Derecho y el Estado

Democrático de Derecho en términos de Teoría del Discurso. Trad. Manuel Jiménez

Redondo. 6 $6^{\mathrm{a}}$ ed. Madrid: Trotta, 2010, p. 202.

47 "Para Habermas, a resposta só poderia ser uma: a facticidade da imposição coercitiva do Direito pelo Estado deveria ser conectada a um processo de normatização racional do direito. Logo, a coerção e a liberdade são dois componentes essenciais à sua validade." CRUZ, Álvaro Ricardo de Souza. Jurisdição Constitucional Democrática. $2^{\underline{a}}$ ed. Belo Horizonte, MG: Arraes Editores, 2014, p. 220. Ainda sobre o tema, conferir CATTONI, Marcelo. Devido Processo Legislativo: uma justificação democrática do controle jurisdicional de constitucionalidade das leis e do processo legislativo. $2^{\underline{a}}$ ed. Belo Horizonte, MG: Mandamentos, 2006.

48 PETTIT, Philip. Teoria da Liberdade. Trad. Renato Sérgio Pubo Maciel. Belo Horizonte, MG: Del Rey, 2007, p. 95

${ }^{49}$ PETTIT, Philip. Teoria da Liberdade. Trad. Renato Sérgio Pubo Maciel. Belo Horizonte, MG: Del Rey, 2007, p. 98-99.

2 JOURNAL OF INSTITUTIONAL STUDIES 2 (2016) 
A teoria do discurso é uma teoria procedimental da correção prática. [...] O procedimento do discurso é um procedimento de argumentação. Isso distingue a teoria do discurso, fundamentalmente, de teorias procedimentais da tradição hobbesiana, que trabalham com procedimentos de negociação e de decisão. ${ }^{50}$

O autor lança luzes sobre a relevância do processo argumentativo que é inerente ao direito, assim como a moral, admitindo que o discurso jurídico é um caso especial do discurso prático geral ${ }^{51}$. Isso reforça a ideia de que o direito possui uma pretensão de correção moral, já que aquele é subconjunto desse, porém, trazendo elementos que são típicos da argumentação jurídica (ex.: debate sobre jurisprudência, princípios jurídicos, etc).

E qual o nexo desse sobrevoo por entre os três autores e a teoria dos "Diálogos Constitucionais"?

A linguagem é pedra basilar de toda a construção que é feita por eles, seja para demonstrar a legitimidade da democracia/direito, seja para referendar liberdades, seja para traçar os contornos do processo argumentativo judicial. E observa-se um cuidado peculiar em desenhar essas premissas.

De maneira contrária, as teorias dialógicas interinstitucionais, em momento algum reservam um capítulo sequer para retratar o que se entende por "diálogos" ou "qual o papel da linguagem". E esse zelo conceitual não pode ser tido por dispensável.

Habermas une intersubjetividade e a busca pelo consenso como partes integrantes da racionalidade que visa caracterizar. No entanto, será que o "consenso interinstitucional" seria uma premissa válida para se avaliar os desempenhos de cada Poder acerca da interpretação constitucional?

Tome-se por base a "prerrogativa de função" retratada na introdução. Será que o fato do voto vencido do Min. Sepúlveda Pertence, quando do cancelamento da Súmula 394, ter feito parte da exposição de motivos da Lei 10.628/02 é apto a admitir que se está diante de "diálogo"? Ou seria um típico exemplo de reação adversarial, tal como um backlash ${ }^{52}$ (com as

${ }^{50}$ ALEXY, Robert. Constitucionalismo Discursivo. Trad. Luís Afonso Heck. 4ª ed. Porto Alegre, RS: Livraria do Advogado, 2015, p. 25.

${ }^{51}$ ALEXY, Robert. Teoría de la Argumentación Jurídica: la Teoría del Discurso

Racional como Teoría de la Fundamentación Jurídica. Trad. Manuel Atienza e Isabel Espejo. Madrid: Centro de Estudios Constitucionales, 1997, p. 205 e ss.

52 "The political grammar of backlash is similar. Backlash expresses the desire of a free people to influence the content of their Constitution, yet backlash also threatens the 
devidas ressalvas de que esse é o termo alcunhado quando o povo se recusa sistematicamente a cumprir uma decisão judicial)?

Veja como há uma incompletude conceitual do termo "diálogos", que é a premissa de todos os autores que propõem essa forma de se investigar o fenômeno da interpretação constitucional. O lugar comum é que durante esse processo inexiste supremacia de um Poder sobre o outro.

Com isso, o segundo passo para a construção dialógica normativa no Brasil seria trazer mais clareza do que seja o diálogo, o que permitiria uma depuração de seu conteúdo frente. Por exemplo, é bem provável que esse "zelo" na classificação permitiria depurar os ataques institucionais das teorias dialógicas. Mas para tanto, é necessário que essas reservem um capítulo para se valer das principais lições acerca da linguagem e discurso. Afinal, o termo que dá nome à teoria... está pendente de significação.

\section{3o PASSO: A SOBREPOSIÇÃO DE FUNÇÕES DO STF E OPINIÃO PúBLICA}

A leitura do art. 102, da Constituição Federal, que supostamente arrefeceria qualquer debate sobre supremacia de outro Poder que não o judicial, traz o rol de competências do STF para além de sua função de Corte Constitucional, a saber o julgamento originário de determinadas autoridades e as funções recursais.

Essa acumulação de funções da Corte, teria alguma implicação quanto à teoria dialógica? Essa pergunta se justifica pelo fato da interpretação constitucional não ser adstrita ao controle judicial de constitucionalidade dos atos administrativos e legislativos.

O debate sobre a institucionalização ou não de um tribunal exclusivamente constitucional esteve presente nos trabalhos da Assembleia Constituinte de 1987-1988. No entanto, essa figura cedeu ante as pressões do próprio Poder Judiciário.

independence of law. Backlash is where the integrity of the rule of law clashes with the need of our constitutional order for democratic legitimacy." Trad. Livre. "A gramática política do backlash é similar. Backlash expressa o desejo de um povo livre influenciar o conteúdo da Constituição, ainda que o backlash ameace a independência do direito. Backlash é onde a integridade do estado de direito luta com a necessidade de uma ordem constitucional para a legitimidade democrática". POST, Robert; SIEGEL, Reva. Roe Rage: Democratic constitutionalism and Backlash. Harvard Civil Rights-Civil Liberties Law Review, Vol. 42, 2, 2007, p. 373-433. 
O anteprojeto de Constituição apresentado à Comissão por José Afonso, como assinalamos, previa explicitamente a figura do Tribunal Constitucional, nos moldes das cortes constitucionais europeias - Alemanha e Itália - de feitio puramente político, dedicado às matérias constitucionais, composto por 15 juízes nomeados pelo Presidente da República, sendo 5 eleitos pelo Conselho Nacional da Magistratura, dentre magistrados dos Tribunais Superiores da União e dos Estados, 5 pelo Congresso Nacional e 5 pelo Conselho de Ministros, dentre juristas de renome e 'comprovada prática democrática'. Estes juízes seriam investidos no cargo por 9 anos, renováveis por terço de três em três anos, vedada a recondução. Além disso, não poderiam ser escolhidos aqueles que estivessem no exercício de mandato executivo ou legislativo, de cargo de Ministro ou Secretário de Estado, o que tivesse exercido qualquer dessas funções até 4 anos antes da escolha. A Comissão Afonso Arinos se encaminhava no sentido de incorporar a sugestão de criação do Tribunal Constitucional, como apresentada no anteprojeto José Afonso da Silva. No entanto, o lobby do Poder Judiciário, especialmente a posição do Supremo Tribunal Federal, que foi formalmente convidado a apresentar propostas à Comissão, impediu a criação da Corte Constitucional. [.... $]^{53}$

É evidente que o acúmulo de funções significa mais poder para a Corte. $\mathrm{O}$ texto constitucional analítico já permitiria que inúmeros temas encontrassem guarida "sob proteção" do STF. E mais eloquente, então, passa a ser essa competência quase que "irrestrita".

Como corolário natural dessa previsão normativa, o STF "julga demais" para um Tribunal que também ocupa a dimensão de Corte Constitucional. Por exemplo, em 2015, foram julgados 2.668 processos, ao passo que ingressaram 86.977 novos, dos quais 73.141 foram distribuídos ${ }^{54}$.

E outro ingrediente que se faz presente diz respeito à relação com a opinião pública. Diversos estudam apontam como essa variável é crucial na performance da Corte, de modo que é habitual as decisões não irem de encontro à suposta vontade da opinião pública ${ }^{55}$. Fator que é

${ }^{53}$ CITTADINO, Gisele. Pluralismo, Direito e Justiça Distributiva: elementos da filosofia constitucional contemporânea. Rio de Janeiro, RJ: Lumen Juris, 1999, p. 3940.

${ }^{54}$ Cf. $<$ http://www.migalhas.com.br/Quentes/17,MI231737,21048$\underline{\mathrm{STF}+\text { faz+balanco+sobre+trabalho+da+Corte+em+2015>. }}$.

55 BARNUM, David. The Supreme Court and Public Opinion: judicial decision making in the Post-New Deal Period. The Journal of Politics, Vol. 47, 2, 1985, p. 652-666; 
inevitavelmente acentuado pela transmissão ao vivo dos julgamentos.

Note o desenho institucional que a teoria dialógica normativa se depara: i) competência amplíssima, sobre os mais variados temas, que por vezes opera como instância originária para processamento; ii) com uma quantidade expressiva de processos a serem julgados; iii) acrescido de uma forte inclinação à opinião pública. O que essas três características sugerem?

Nesse caso, as teorias dialógicas são férteis e úteis para análise. Isso porque essa corrente parte tem como premissa a ideia de que o Judiciário, assim como os outros Poderes, possui uma conotação política ${ }^{56}$. Nesse sentido, qualquer análise que fizesse uma espécie de filtragem quanto ao papel político desempenhado pela Corte (ou fizesse uma "leitura técnica" sobre sua atuação) seria fadada ao fracasso.

E de que forma a mediação para uma teoria normativa lidaria com as características mencionadas? Dois aspectos:

1) O desenho institucional é a variável mais importante na análise de qualquer teoria que busque avaliar a performance da interpretação constitucional dos atores políticos. Logo, uma teoria dialógica normativa brasileira deve vir acompanhada de uma descrição detalhada de como as instituições operam no Brasil. Esse ponto será resgatado no quarto passo; e

2) A comparação da interpretação constitucional feita pelas instituições é indissociável da política, pois se baseia que até mesmo o Judiciário pera como um ator político nesse cotejo. Por conseguinte, uma teoria dialógica normativa deve ser interdisciplinar, com os fundamentos alicerçados tanto no arcabouço teórico da ciência política, quanto do direito.

MARSHALL, Thomas; IGNAGNI, Joseph. Supreme Court and public support for right claims. Judicature, Vol. 78, 3, 1994; e NOVELINO, Marcelo. O STF e a Opinião Pública. In: Daniel Sarmento (Org.). Jurisdição Constitucional e Política. Rio de Janeiro, RJ: Editora Forense, 2015.

${ }^{56}$ O título do livro de Louis Fisher, por exemplo é “Diálogos Constitucionais: interpretação como processo político". Cf. FISHER, Louis. Constitutional Dialogues: Interpretation as Political Process. Princeton, NJ: Princeton University Press, 1988. 


\section{4o Passo: "Nova SeParação de Poderes"}

O passo anterior demonstrou como é relevante os desenhos institucionais na mediação de uma teoria dialógica normativa, especialmente dada a peculiar caracterização do STF no Brasil.

Dando o passo seguinte, a Separação de Poderes também não pode ser colocada de lado. Ou melhor, a "Nova Separação de Poderes", tal como propõe Bruce Ackerman.

Mas, no século XXI, precisamos de um modelo muito mais amplo, capaz de suscitar comparações sistemáticas em uma escala mundial, e reflexões normativas informadas a partir das contínuas lições da experiência ${ }^{57}$

O autor propõe uma releitura do modelo tripartite de Montesquieu, inclusive demonstrando sua incongruência com os atuais desenhos institucionais e a preocupação de como os novos atores se justificam em uma democracia. Para Ackerman, quatro pressupostos devem ser preenchidos, para se averiguar a legitimidade das "novas" instituições, que não se resumem ao Legislativo, Judiciário e Executivo:

1) Ligação com o valor democracia (ou teorias econômicas, no caso do Banco Central);

2) Recusa de que agentes políticos autointeressados estejam a frente dessas instituições;

3) Insulamento dessas instâncias, que conduzirá a um trabalho melhor; $\mathrm{e}$

4) Análise empírica comparativa de como instituições "independentes" funcionam em outros países.

Transpondo as lições de Ackerman para o Brasil, os novos centros de poder (novos atores políticos para além dos tradicionais) ganham cada vez mais proeminência. Exemplifique-se o Ministério Público e sua influência na agenda pública e canalização dos movimentos sociais,

${ }^{57}$ ACKERMAN, Bruce. Adeus, Montesquieu. Revista de Direito Administrativo, Vol. 265, 2014, p. 14. 
Banco Central e sua normatividade acerca da economia, veículos de comunicação, entidades paraestatais, agências reguladoras...

Com isso, as possibilidades de diálogos se multiplicam de maneira exponencial, já que as interações podem ser arranjadas de várias maneiras. Sem contar que os diálogos entre as (novas) instituições podem desembocar em um verdadeiro diálogo multitudinário.

Uma teoria normativa dialógica daria conta dessa "Nova Separação de Poderes"? Seria o departamentalismo um modelo mais promissor que a "promessa dialógica"?

Veja como seria importante a clareza conceitual do termo "diálogo", tal como salientado no segundo passo. É bem verdade que quanto maior o círculo de possíveis interlocutores desse diálogo, mais difícil seria traçar os contornos da teoria, já que as relações interinstitucionais podem reservar peculiaridades para além de premissas universais. Mas uma consideração de relevo pode ser apontada. Trata-se da necessidade de "levar a sério" a interpretação sobre o mesmo tema feita por outro poder.

Nesse momento, a teoria dos standards criada pela Suprema Corte no caso United States v. Carolene Products (304 US 144 1938) é elucidativa para o presente raciocínio. O exercício do judicial review seria mais severo conforme os direitos que estivessem sendo discutidos ${ }^{58}$ :

i) Teste de racionalidade: casos cujo controle de constitucionalidade das normas deveria ser mais brando, tais como a envolver regras de intervenção do Estado na economia;

ii) Teste intermediário: meio caminho entre o teste de racionalidade e o escrutínio estrito; e

iii) Escrutínio estrito: quase uma presunção de inconstitucionalidade, por exemplo, quando se estivesse diante de normas restritivas de direitos fundamentais.

Ancorados nesse padrão, Daniel Sarmento e Cláudio Souza Neto propõem os seguintes standards ${ }^{59}$ :

58 Sobre o tema, conferir CAMPOS, Carlos Alexandre de Azevedo. Dimensões do ativismo judicial do STF. Rio de Janeiro, RJ: Forense, 2014.

${ }^{59}$ SARMENTO, Daniel; SOUZA NETO, Cláudio Pereira de. Controle de

Constitucionalidade e Democracia: algumas teorias e parâmetros de ativismo. In:

Daniel Sarmento (Org.). Jurisdição Constitucional e Política. Rio de Janeiro, RJ:

Editora Forense, 2015. 
1) Grau de legitimidade democrática do ato impugnado: observa-se como foi o processo legislativo e grau de adesão popular (quanto mais legítimo, mais contido);

2) Proteção aos pressupostos da democracia: tais como direitos políticos e direitos de liberdade (mais ativista);

3) Defesa de minorias vulneráveis/estigmatizadas (mais ativista);

4) Defesa de direitos básicos e liberdades existenciais (mínimo existencial) (mais ativista);

5) Comparação de capacidades institucionais: por exemplo, menor tecnicidade e expertise do Judiciário (a depender do tema, mais contido);

6) Época do ato normativo (mais ativista, conforme mais antigo o período); e

7) Inconsistência temporal ou o que pode ser melhor para a comunidade no futuro (mais ativista)

Essas sugestões acerca da postura do Judiciário são absolutamente válidas. Todavia, partem da premissa de que esse Poder terá a última palavra no tocante à interpretação constitucional. Premissa essa que a teoria dialógica se ocupa por descartar

Contudo, elas reforçam o que fora dito acima: a necessidade de se verificar a interpretação constitucional capitaneada por cada Poder (rectius, por cada ator político, firme na "Nova Separação de Poderes", bem como pela própria sociedade). Sugere-se que o processo de tomada de decisão de cada ator traga razões pelas quais está se discordando da interpretação feita por outra instituição. Por exemplo, a exposição de motivos de uma proposição legislativa deve conter a razão pela qual não se está adotando a interpretação do Judiciário, caso esse já tenha se manifestado sobre o tema, bem como dos movimentos sociais afetos a tal proposição. E o mesmo vale para o dia a dia da atuação do Ministério Público, Banco Central, Tribunais de Contas, e todas as instituições que compõem a "Nova Separação de Poderes". 


\section{CONCLUSÃO}

O presente ensaio demonstrou que é possível sim falar em teoria normativa dialógica brasileira, contanto que seja feita uma mediação apta a levar a sério o contexto pátrio subjacente. Mais uma vez, a mediação é condição para qualquer teoria que fora criada no em país diverso do qual se teste sua aplicabilidade. A tarefa é ainda mais importante quando se depara com as diferenças marcantes entre tais países.

Diante dessa situação, a teoria dialógica normativa deve dar conta de quatro passos:

$\left.1^{9}\right)$ enxergar as instituições como reflexo das assimetrias sociais (e econômicas) presentes na sociedade. Logo, explicar de que forma a interpretação constitucional não seria caudatário desse cenário.

$2^{\circ}$ ) clareza conceitual quanto à premissa que dá nome a própria teoria, qual seja "diálogos". Por isso a necessidade de reservar um espaço (capítulo, tópico, seção...) destinada a explorar as principais lições acerca da interface direito, democracia e linguagem.

$3^{\circ}$ ) a sobreposição de funções do STF dá pistas de como o desenho institucional é extremamente relevante para qualquer tipo de prescrição acerca da interpretação constitucional entre os Poderes. Além disso, o estudo não pode prescindir da interdisciplinaridade com a ciência política, visto que se interpreta o Judiciário como ator político.

$\left.4^{\circ}\right)$ a partir dos desenhos institucionais, a teoria dialógica normativa deve ter como fio condutor a percepção de que se está diante de uma "Nova Separação de Poderes". Esse aspecto tem total pertinência com a interpretação constitucional, a considerar que o círculo de intérpretes se expande e a teoria não pode deixar certa instituição fora de sua abrangência. Se o fizer, a justificativa tem que ser de relevo.

\section{REFERÊNCIAS}

ABRAMOVAY, Pedro. Separação de Poderes e Medidas Provisórias. Rio de Janeiro, RJ: Elsevier, 2012. 
ABRANCHES, Sérgio Henrique. Presidencialismo de Coalizão: o dilema institucional brasileiro. Dados: Revista de Ciências Sociais, Vol. 31, 1, 1988.

ACKERMAN, Bruce. Adeus, Montesquieu. Revista de Direito Administrativo, Vol. 265, 2014.

ACKERMAN, Bruce. The New Separation of Powers. Harvard Law Review, Vol. 113, 3, 2000.

ALEXY, Robert. Constitucionalismo Discursivo. Trad. Luís Afonso Heck. 4ª ed. Porto Alegre, RS: Livraria do Advogado, 2015. . Teoría de la Argumentación Jurídica: la Teoría del Discurso Racional como Teoría de la Fundamentación Jurídica. Trad. Manuel Atienza e Isabel Espejo. Madrid: Centro de Estudios Constitucionales, 1997.

BADARÓ, Gustavo Henrique. Processo Penal. 3ae ed. São Paulo, SP: Ed. Revista dos Tribunais, 2015.

BARNUM, David. The Supreme Court and Public Opinion: judicial decision making in the Post-New Deal Period. The Journal of Politics, Vol. 47, 2, 1985.

BARROSO, Luís Roberto. A razão sem voto: o Supremo Tribunal Federal e o governo da maioria. Revista Brasileira de Políticas Públicas, Vol. 5, 2, 2015.

. O Novo Direito Constitucional Brasileiro: contribuições para a construção teórica e prática da jurisdição constitucional no Brasil. Belo Horizonte, MG: Editora Fórum, 2013. 
BATEUP, Christine. The Dialogic Promise: assessing the normative potential of Theories of Constitutional Dialogue. Brooklyn Law Review, Vol. 71, 3, 2006.

BRANDÃO, Rodrigo. Supremacia Judicial versus diálogos constitucionais: a quem cabe a última palavra sobre o sentido da Constituição? Rio de Janeiro, RJ: Lumen Juris, 2012.

BRASIL, INSTITUTO BRASILEIRO DE GEOGRAFIA E ESTATÍSTICA (IBGE). Pesquisa Nacional por Amostra de Domicílios (PNAD): Brasil e Síntese de Indicadores 2013. Disponível em:

$<<$ http://www.ibge.gov.br/home/estatistica/populacao/trabalhoerendime nto/pnad2013/>. Acesso em: 05 de outubro de 2016.

. Pesquisa Nacional por Amostra de Domicílios Contínua: $2^{\circ}$

trimestre 2016. Disponível em:

$<$ http://www.ibge.gov.br/home/estatistica/pesquisas/anos anteriores 20 16.shtm>. Acesso em: 05 de outubro de 2016.

BRASIL, MINISTÉRIO DA JUSTIÇA, DEPARTAMENTO

PENITENCIÁRIO NACIONAL (DEPEN). Levantamento Nacional de Informações Penitenciárias INFOPEN: Junho de 2014. Disponível em: $<$ http://www.justica.gov.br/noticias/mj-divulgara-novo-relatorio-doinfopen-nesta-terca-feira/relatorio-depen-versao-web.pdf $>$. Acesso em: 06 de outubro de 2016.

CAMPOS, Carlos Alexandre de Azevedo. Dimensões do ativismo judicial do STF. Rio de Janeiro, RJ: Forense, 2014.

CATTONI, Marcelo. Devido Processo Legislativo: uma justificação democrática do controle jurisdicional de constitucionalidade das leis e do processo legislativo. $2^{\underline{a}}$ ed. Belo Horizonte, MG: Mandamentos, 2006. 
CHEIBUB, José Antonio; PRZEWORSKI, Adam; SAIEGH, Sebastian. Governos de coalizão nas democracias presidencialistas e parlamentaristas. Dados: Revista de Ciências Sociais, Vol. 45, 2, 2002.

CITTADINO, Gisele. Pluralismo, Direito e Justiça Distributiva: elementos da filosofia constitucional contemporânea. Rio de Janeiro, RJ: Lumen Juris, 1999.

CRUZ, Álvaro Ricardo de Souza. Jurisdição Constitucional

Democrática. $2^{\underline{a}}$ ed. Belo Horizonte, MG: Arraes Editores, 2014.

DWORKIN, Ronald. Justiça para ouriços. Trad. Pedro Elói Duarte. Coimbra: Almedina, 2011.

. O Direito da Liberdade: a leitura moral da Constituição norteamericana. Trad. Marcelo Brandão Cipolla. São Paulo, SP: Martins Fontes, 2006.

ELSTER, Jon. Ulysses and the Sirens: studies in rationality and irrationality. Cambridge, MA: Cambridge University Press, 1984.

. Ulisses liberto: estudos sobre racionalidade, pré-compromisso e restrições. Trad. Cláudia Sant'Ana Martins. São Paulo, SP: Editora UNESP, 2009.

FISHER, Louis. Constitutional Dialogues: Interpretation as Political Process. Princeton, NJ: Princeton University Press, 1988.

GINSBURG, Tom. The Global Spread of Constitutional Review. In: Keith Whittington; Daniel Keleman; Gregory Caldeira (eds.). Oxford Handbook of Law and Politics. New York, NY: Oxford University Press, 2008. 
GINSBURG, Tom; VERSTEEG, Mila. Why do Countries adopt constitutional review? The Journal of Law, Economics \& Organization, Vol. 30, 3, 2014.

HÄBERLE, Peter. Hermenêutica Constitucional: a sociedade aberta dos intérpretes da Constituição. Contribuição para a interpretação pluralista e "procedimental" da Constituição. Trad. Gilmar Ferreira Mendes. Porto Alegre, RS: S.A. Fabris Editor, 2002.

HABERMAS, Jürgen. Facticidad y Validez: sobre el Derecho y el Estado Democrático de Derecho en términos de Teoría del Discurso. Trad. Manuel Jiménez Redondo. 6 ${ }^{\underline{a}}$ ed. Madrid: Trotta, 2010.

HIEBERT, Janet. Charter conflicts: what is the Parliament role? Montreal: McGill-Queen's University Press, 2002.

. Enriching Constitutional Dialogue: viewing Parliament's role as both proactive and reactive. Ottawa: Research and Statistics Division, 2000.

HIRSCHL, Ran. The Political Origins of the New Constitutionalism. Indiana Journal of Global Legal Studies, Vol. 11, 1, 2004.

HOGG, Peter; BUSHELL, Alisson. The Charter Dialogue between Courts and Legislatures (Or Perhaps the Charter of Rights isn't such a bad thing after all). Osgoode Hall Law Journal, Vol. 35, 1, 1997.

JORDÃO, Eduardo; ROSE-ACKERMAN, Susan. Judicial Review of Executive Policymaking in advanced democracies: beyond rights review. Administrative Law Review, Vol. 66, 1, 2014.

KRAMER, Larry. Popular Constitutionalism, circa 2004. California Law Review, Vol. 92, 4, 2004. 
MARSHALL, Thomas; IGNAGNI, Joseph. Supreme Court and public support for right claims. Judicature, Vol. 78, 3, 1994.

MENDES, Conrado Hübner. Direitos Fundamentais, Separação de Poderes e Deliberação. São Paulo, SP: Saraiva, 2011.

NEIVA, Pedro; IZUMI, Maurício. Perfil profissional e distribuição regional dos senadores brasileiros em dois séculos de história. Revista Brasileira de Ciências Sociais, Vol. 29, 84, 2014.

NEVES, Marcelo. Entre Têmis e Leviatã: uma relação difícil. $3^{a}$ ed. São Paulo, SP: Wmf Martins Fontes, 2012.

NINO, Carlos Santiago. The Constitution of Deliberative Democracy. New Haven, CT: Yale University Press, 1996.

NORTON, Andrew; ELSON, Diane. What's behind the budget? Politics, rights and accountability in the budget process. London: Overseas Development Institute, 2002.

NOVELINO, Marcelo. O STF e a Opinião Pública. In: Daniel Sarmento (Org.). Jurisdição Constitucional e Política. Rio de Janeiro, RJ: Editora Forense, 2015.

PETTIT, Philip. Teoria da Liberdade. Trad. Renato Sérgio Pubo Maciel. Belo Horizonte, MG: Del Rey, 2007.

POST, Robert; SIEGEL, Reva. Roe Rage: Democratic constitutionalism and Backlash. Harvard Civil Rights-Civil Liberties Law Review, Vol. 42, 2, 2007.

$\mathrm{ROACH}$, Kent. The Supreme Court on trial: judicial activism or democratic dialogue. Toronto: Irwin Law, 2001. 
SAMPAIO, Marco Aurélio. A Medida Provisória no Presidencialismo Brasileiro. São Paulo: Malheiros, 2007.

- Medida Provisória, Diálogo Constitucional e a Falácia de Usurpação de Poderes Legislativos pelo Executivo. Revista de Direito do Estado, Vol. 1, 4, 2006.

SARMENTO, Daniel; OSORIO, Aline. Eleições, Dinheiro e Democracia: a ADI 4.650 e o modelo brasileiro de financiamento de campanhas eleitorais. Direitos Fundamentais \& Justiça, Ano 8, no 26, 2014.

SARMENTO, Daniel; SOUZA NETO, Cláudio Pereira de. Controle de Constitucionalidade e Democracia: algumas teorias e parâmetros de ativismo. In: Daniel Sarmento (Org.). Jurisdição Constitucional e Política. Rio de Janeiro, RJ: Editora Forense, 2015.

STONE SWEET, Alec. Constitutional Courts. Yale Law School Public Law Working Paper, No. 233, 2011.

STRECK, Lenio Luiz. Bem jurídico e Constituição: da Proibição de Excesso (Übermassverbot) à Proibição de Proteção Deficiente (Untermassverbot) ou de como não há blindagem contra normas penais inconstitucionais. Boletim da Faculdade de Direito (Universidade de Coimbra), Vol. LXXX, 2004.

VIEIRA, Oscar Vilhena. A desigualdade e a subversão do Estado de Direito. In: Daniel Sarmento; Daniela Ikawa; Flávia Piovesan.

Igualdade, Diferença e Direitos Humanos. Rio de Janeiro, RJ: Lumen Juris, 2008.

. Supremo Tribunal Federal: Jurisprudência Política. $2^{\underline{a}}$ ed. São Paulo, SP: Malheiros, 2002. 
WALDRON, Jeremy. Law and Disagreement. New York, NY: Oxford University Press, 1999.

É Possível Falar em Teoria Normativa Dialógica no Brasil? Is it Possible to Talk about a Normative Dialogical Theory in Brazil?

Submetido em: 2016-11-20 